\title{
Resuscitation trolleys: human factors engineering
}

An essential part of nursing education in the early 1950s was to prepare a special "tray" for different procedures. A textbook, "Tray and Trolley Setting" by Helene Dickie, ${ }^{1}$ gave accurate instructions and drawings for the preparation of equipment and drugs for the most important procedures such as colonic lavage, mustard plaster application, and many more. On page 138 is an illustration showing the trolley for tracheotomy (see front cover). This is a well designed set up as the operator can see the equipment and has easy access to whatever he needs.

Cardiopulmonary resuscitation (CPR), introduced by $\mathrm{P}$ Safar in 1964, required only 10 fingers, the knowledge to perform mouth to mouth ventilation, and the proper way for cardiac massage. Advanced cardiac life support was the next step; equipment and drugs were supposed to be handy and portable so that they could be carried to the patient's bed or in the ICU for rapid and easy access. Today the essential equipment for resuscitation includes more than 100 items-drugs, syringes, electrodes, etc-and easy access to electrical power.

In the same way that nurses prepared their trolleys in the past, in the operating room all the necessary items for CPR were located in a special place, usually on a "cart" (fig 1). A similar cart was built for the emergency room and for patient wards. All were designed without regard to basic human factors design. The first carts were simple adaptations of the multiple drawer trolley used by mechanics in auto repair shops (fig 2). Careful analysis from a human engineering view showed that, even though it was easy to mobilize the cart, it was hard to locate drugs in the different compartments and at "time crucial"

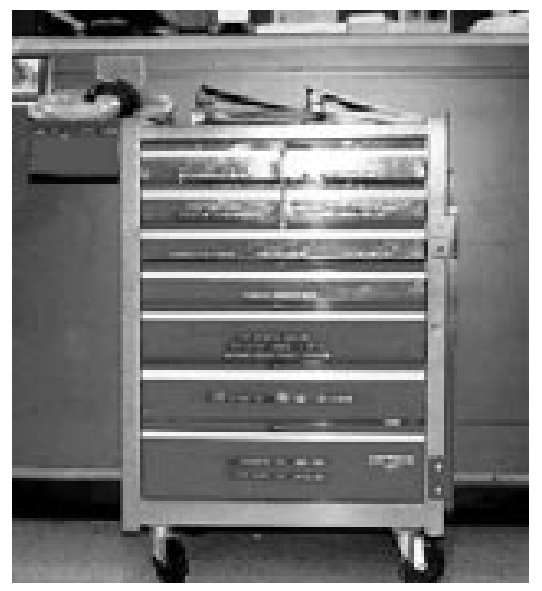

Figure 1 Early design of a CPR "cart." moments one drawer would not let the other one open properly. For those who used this cart for the first time during a CPR event, it was time consuming to locate a $5 \mathrm{ml}$ syringe or to find a drug ampoule. Commercial CPR trolleys soon became available but they were different from the generic "tool shed" ones. The drawers were larger in order to store large items such as a manual bag ventilator and multiple size masks. A lock to protect the drugs and wheels for easy transport were added; but human factors engineering was still neglected. The carts were designed as a simple storage place without taking into account the needs encountered during moments of crisis and high tempo which regularly occur during a cardiac arrest.

Recording CPR by video analysis helped to map out the process and led us to suggest a different approach to the design of CPR trolleys. What was wrong?

(1) Drugs and the equipment necessary to deliver them were usually opaque to the clinicians, hidden and, even after the item was located, access was not easy.

(2) There is a need for many electrical sockets to power the devices used during resuscitation but which are not readily available around the patient's bed.

(3) Labeling was not apparent and went against all rules of human factors design (see paper by Gosbee in this issue of QSHC). ${ }^{2}$

\section{HUMAN FACTOR DESIGNED RESUSCITATION TROLLEYS}

From the information gathered we designed a CPR trolley based on the supermarket principle that all merchandise should be seen and easily accessible to the customer ("touch and buy"). Transparent containers that opened towards the operator served as a basic model for our prototype. Various sizes of containers were put together on a frame with wheels. No labeling was necessary as all items were

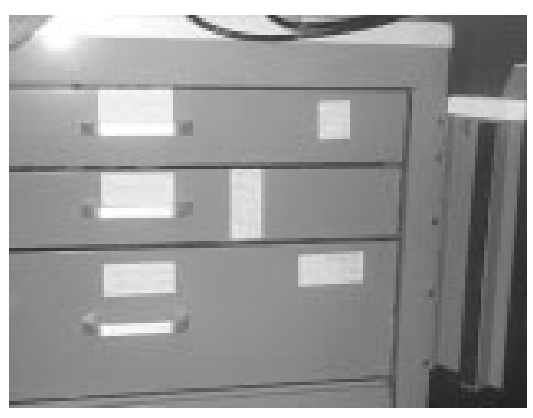

Figure 2 Multiple drawer trolley. transparent to the users. There were no drawers. Suction catheters and bulky items were stored in perpendicular pipes, and 10 electrical sockets were built into the frame with only one (very long) electrical extension cord needed to power the trolley and the resuscitation devices required during CPR (fig 3).

At first the nurses did not like the new cart. They thought that, if you can see the equipment and drugs, they would disappear. They also felt that it would be difficult to clean. However, after using it for the first time in a real resuscitation event, they never wanted to go back to the old "tool shed" trolleys. Today this is the standard CPR trolley in our hospital and in most hospitals in Israel. This is an example of how the application of relatively "simple" human factors principles can lead to a significant improvement in reducing errors in a medical work environment. By using interviews, focus groups, mapping out the process, and applying video task analysis we were able to capture the real needs of the healthcare providers and to design a useful tool that reduced their workload and also improved the care of patients.

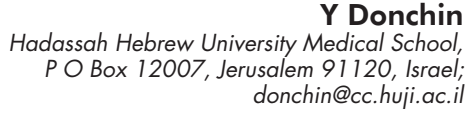

\section{REFERENCES}

1 Dickie H. Tray and trolley setting. London: Livingston Ltd, 1963.

2 Gosbee J. Human factors engineering and patient safety. Qual Saf Health Care 2002;11:352-4.

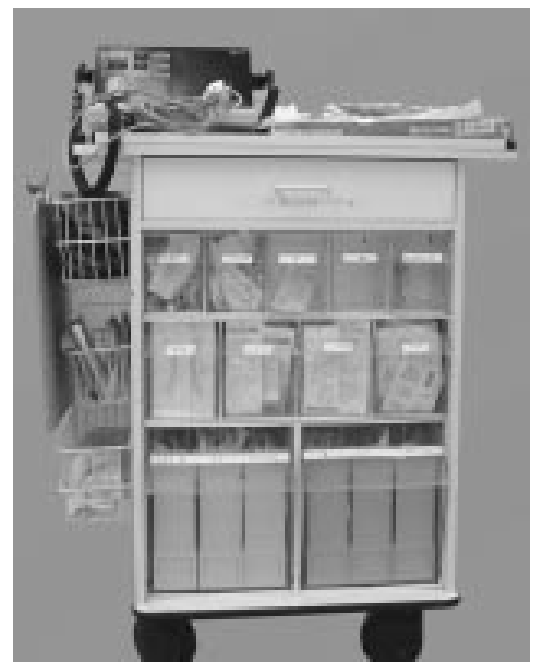

Figure 3 Human factor designed resuscitation trolley. 